\title{
Practice, Habitus, and Lived Religion
}

\section{Approaching Religion through Practice}

Practice theory is a strand of social scientific theorization which attributes to practice a particularly fundamental role in the formation and functioning of the social world (Ortner 1984). The concept of practice refers to human activity which simultaneously constructs both individuals as social beings and the social world that surrounds them (Ortner 2006, 129; Ortner 1989, 11-12; Sewell 1992, 5). Through their activities, individuals internalize cultural symbols and meanings. Through the same activities, they also reproduce and transform these symbols and meanings in the social world. This is the central premise of theories of practice.

The use of the term "practice" in contemporary religious scholarship often signals some form of alignment with practice theory. There is, for instance, a growing interest in the intertwinement of the self and the social world in daily religious activity (e.g., Bowman and Valk 2012; Giordan and Swatos 2011; Morgan 1998). The concern with the everyday, moreover, is often coupled with an emphasis on the body as the locus of religious practice and on embodied practices as the foundation of religious identities (e.g., Csordas 1994; Lester 2005; Trulsson 2010). Other scholars, for their part, have focused on the social structures informing religious practices, and on the struggles for their reproduction and reform (e.g., Asad 2003; Asad 1993; Ortner 1989; Tweed 2006; Wood 2007).

Since its development into a distinct research field, lived religion has been closely connected to practice theory (e.g., Hall 1997a, xi; Orsi 2003, 174; Orsi $1997,7)$. In essence, it promotes a practice-oriented approach to religious phenomena. The concept of lived religion refers to religion as something that is continuously being made and remade by individuals engaging in religious activities and using religious idioms - laymen, religious specialists, and policymakers alike. Within the lived religion paradigm, moreover, this conceptualization of religion as ongoing "cultural work" (Orsi 2003, 172) is expanded to include religious scholarship as well.

In recent years, scholars of religion have become increasingly aware of the historical baggage carried by conventional academic definitions of religion; that is to say, their intertwinement, for instance, with Reformation and colonialist discourses (Asad 1993, 27-54; McGuire 2008, 20-24, 39-41; Orsi 2012, 
$3^{-6}$; Riesebrodt 2010, 1-20). One of the reactions to this crisis of definition has been to promote the abandoning of normative interpretations of religion as a starting point of analysis in favor of emphasizing individuals' concrete practices and articulated beliefs that the individuals themselves consider to be religious (McGuire 2008, 4; Primiano 1995, 40). However, since individuals' views are always influenced by cultural meanings and valuations, it is equally important to focus on discourses concerning religion, on how the category of religion is being constructed in particular societies at particular times (Beckford 2003, 20-21; von Stuckrad 2010, 166). Furthermore, to acknowledge the role that academia plays and has played in this process, it is necessary to conceive of the scholarly enterprise as one endeavor among others concerning religion - one that affects, and is affected by, social structures and cultural categorizations. In the lived religion paradigm, the pursuit of this kind of historical selfconsciousness is paramount (Orsi 2003, 171-172).

Nevertheless, analytic definitions of religion still have relevance. For instance, on them rests the possibility of reaching comparative understandings and general theorizations concerning phenomena that, within particular contexts, are understood to be religious (Konieczny, Lybarger, and Chong 2012, 399-402; Riesebrodt 2010, 15-19). However, it is important to conceive of academic definitions as tools that have been constructed for tackling particular research questions. They are never neutral, comprehensive, or conclusive, and are always in some respects situational and instrumental (Tweed 2006, 29-53).

In this book, I analyze evacuee Karelian Orthodox women's accounts of their own practices and beliefs which in their view are religious. However, my method has not been entirely inductive, as existing, normative discourses concerning religion also played a role in the interview situations. During the course of the analysis, moreover, I also formulate propositions about the women's religious habitus, religious agency, and the religious field they are embedded in. This necessitates an analytical take on religion.

In his practice-oriented theory of religion, sociologist of religion Martin Riesebrodt (2010, 74-76) defines religion as a "complex of practices that are based on the premise of the existence of superhuman powers, whether personal or impersonal." According to him, religious practices typically consist of establishing contact with these powers, or gaining access to them, through culturally prescribed means. The category of superhuman powers, as described by Riesebrodt, is not an unambiguous one. However, he argues that it provides a "content-based and widely accepted" premise for the religious, which constitutes a more appropriate basis for defining religion than, for instance, functional premises that overlook "the meaning of religion from the point of 
view of religious practitioners and thus also from that of the theory of action" (Riesebrodt 2010, 72-75).

Leaning on Riesebrodt, I also espouse the idea that what is specific about religious practice is the postulation of non-empirical forces as part of the structures of social experience constructed through and constructive of this practice (see also Rubin, Smilde, and Junge 2014, 10, 14). This criterion is workable in that it provides the opportunity to differentiate between religious and non-religious practice, while, importantly, not contradicting the Orthodox women's self-understandings concerning religion. However, I want to make one clarification, below, to Riesebrodt's definition.

As part of the general re-appraisal of the basic concepts of the discipline, scholars of religion have increasingly begun to question the taken-for-granted use of binary categories such as sacred/profane and transcendent/mundane in research on religion (e.g., Day, Vincett, and Cotter 2013, 1-2). Lived religion, after all, can rarely be arranged into such neat dualisms. In this vein, anthropologist Martin Stringer $(2008,8-10,63-64,81-82)$ criticizes the idea of "transcendent" that is inherent in many classic definitions of religion. He argues that lay individuals, even in the Protestant West, do not necessarily experience religious entities as something "radically other." In his theory, Riesebrodt uses the term "superhuman" for the non-empirical; Bourdieu's chosen term, as discussed in the next section, is "supernatural." Against the overtones carried by these terms, I want to emphasize that I do not see the non-empirical as constituting only something radically separate from the mundane world. Instead of being something "super" compared to ordinary and normal, it is often a part of everyday life.

\section{The Religious Field}

The French sociologist Pierre Bourdieu (1930-2002) was one of the most widely discussed social theorists of the latter half of the 2oth century. Along with sociologist Anthony Giddens' $(1984 ; 1979)$ structuration theory, his theory of practice (Bourdieu 199ob; Bourdieu 1977) constitutes the most well-known formulation of practice theory. The goal of the theory, according to Bourdieu, is to transcend dualistic conceptualizations of the social world that dominate in the social sciences. To him, that is, the apparently irreconcilable points of view in such dichotomies as objectivism/subjectivism, society/individual, and structure/action actually stand in a dialectical relationship. Their artificial opposition can be overcome by applying to the social world a way of thinking 
which "identifies the real not with substances but with relations" (Bourdieu 1990a, 124-126; Wacquant 1992, 7-11).

The core trio of concepts in Bourdieu's theoretical apparatus - field, capital, and habitus - is geared to facilitate a relational analysis of social phenomena (Grenfell 2008b, 220-222). In Bourdieuan vocabulary, the concept of field refers to semi-autonomous configurations of relations in the social world, within which individuals, interest groups, and institutions are positioned (Bourdieu and Wacquant 1992, 98-101; see also Postone, LiPuma, and Calhoun 1993, 4-6; Rey $2007,44-45,51,53)$. In each field, individuals compete for power. Capital denotes the different kinds of resources, values, and wealth around which crystallize the power relations in any field. Thus, within each field, the competition for power translates into a struggle for the accumulation and control of capital as delineated by the logic of the field in question. Finally, Bourdieu (199ob, 53) defines habitus as systems of incorporated dispositions which inform individuals' actions within different fields.

Although Bourdieu's social theory is much indebted to social scientists of religion (such as Emile Durkheim, Max Weber, and Marcel Mauss), the sociology of religion was of marginal concern to him (Dianteill 2003, 529; Rey 2007, 8-9). Altogether, he wrote only a few texts that deal explicitly with religion. The most important of these are his two essays from 1971 (Bourdieu 1971a; Bourdieu 1971b) that theorize the "genesis and structure of the religious field" and the relations between different agents within this field.

In these articles, Bourdieu (1971a, 300-305, 318-320; 1971b, 7-11; 1991a, 5-9, 22-25) argues that the division of labor fostered by urbanization constitutes the necessary condition for the emergence of an independent religious field. This field extends between different religious specialists who control religious knowledge and are in competition for religious capital. In Bourdieu's (1971a, 311-316, 328-334; 1991a, 5, 14-19, 31-38) view, the first and foremost function of religion is to legitimize social classifications and inequalities, an effect created by the collective misrecognition of the economic and power relations behind the religious specialists' work of transfiguring "social relations into supernatural relations." However, in modern and differentiated societies, the state has assumed the role of the primary legitimizer of the social arbitrary, which to Bourdieu denotes an inevitable decline in the significance of religion (Dianteill 2003, 541-543, 546; Engler 2003, 450).

Bourdieu's writings on religion do not include a full-fledged definition of it. In fact, formulating such a definition would go against his theorizations, since his interpretation of the religious field presupposes that the power to define what constitutes religion is one of the issues at stake in the field's struggles 
(see Bourdieu 2010, 6). However, in explicating the interest underlying all activities within the field, he follows a Weberian understanding of religion as connected to the organization of the relationship between man and supernatural powers, and, furthermore, the cultivation of this relationship into "goods of salvation": the means to deal with anxieties related to the existence of evil, injustice, suffering, and death (Bourdieu 1971a, 311-313; Bourdieu 1991a, 15-17; see also Rey and Stepick 2013, 14; Wood 2007, 66-68). ${ }^{1}$ For Bourdieu, then, activity within the religious field hinges on the belief that supernatural entities and powers exist, and that they can influence the natural world. Importantly, this understanding of the religious field is compatible with Martin Riesebrodt's (2010) also essentially Weberian definition of religion, with which I sided in the previous section.

Bourdieuan social theory has not gained the kind of status within religious studies that it holds in many other fields of study. A central reason for this, evidently, is that Bourdieu's work concerning religion has often been deemed lacking in sophistication (e.g., Hervieu-Léger 2000, 110-111). Based on the historical case of French Catholicism, Bourdieu's account of the religious field focuses on a situation in which a particular institution holds a monopoly over the whole field. It cannot be applied, as such, to more religiously pluralistic societies.

However, Bourdieu never actually designed his concept of field for this kind of uncritical use. Rather, he emphasized the necessity of empirical research in determining the existence and the boundaries of any specific field in any given time and place (Bourdieu and Wacquant 1992, 100-101). In this vein, Bourdieu's theorizations on religion have been used to successfully identify local religious fields and capital, and to analyze religious specialists' strategies for accumulating power and position, in various geographical and historical contexts (Fer 2010; Ladwig 2011; Maduro 2005; McKinnon, Trzebiatowska, and Brittain 2011; Rey 1998; Urban 2003). Several recent studies inquire specifically into the organization of the religious field under conditions of heightened pluralism (Wood 2007; Wood and Bunn 2009). Other contributions, for their part, discuss the intertwinement of the religious field with other fields, such as those of art and healing (Lindquist 2006; Malmisalo 2005; see also McCloud 2007; Verter 2003).

Overall, Bourdieuan social theory has been commended for its potential to discern and highlight power hierarchies and conflicts within religious fields (Maduro 2012, 35; Rey 2007, 5, 45). At the same time, Bourdieu's own account of the religious field has received much criticism for treating lay believers as mere

1 The reliance on Weber is not surprising, for Bourdieu's whole conceptualization of the religious field is heavily influenced by Weber's (1978) interpretation of religion (Bourdieu 1971a; Bourdieu 1971b; Rey 2007, 72-75; Swartz 1996). 
pawns in the power games of specialists (e.g., Dillon 2001, 414-415; Verter 2003, 157). After all, Bourdieu (1971a, 304; 1991a, 9) explicitly speaks of the laity as "dispossessed of religious capital," and therefore dependent on religious specialists to satisfy their religious needs. This statement, however, actually describes only one possible configuration of the religious field. While Bourdieu's account focuses mostly on this particular structuring of the field, characterized by the specialists' monopoly over religious production, his theory also acknowledges the possibility of laymen's "religious self-sufficiency" (Bourdieu 1971a, 305; Bourdieu 1991a, 9-10; see also Kühle 2012a, 10-11). Nonprofessionals' possession and wielding of religious capital has also been demonstrated through studies on their participation in struggles within the religious field (Dillon 2001; Stone 2001; Verter 2003). ${ }^{2}$

Another criticism that many scholars of religion have leveled against Bourdieu is that in his theorizations concerning religion he focuses on issues not specific to it. Martin Riesebrodt, for example, notes that, in conceiving of the religious field as an arena of competition for religious capital homologous to other fields, Bourdieu "reduces religion to an instrument for pursuing thisworldly power interests and social advancement" (Riesebrodt 2010, 67; see also Hämmerli 2011, 199-203; Swartz 1996, 82-84). This accusation echoes a more general critique that disapproves of the prevalence of the "metaphor of economy" (Heiskala 2000, 183-184) in Bourdieuan social theory. Indeed, Bourdieu's discussions surrounding the concept of capital, especially, suggest that all meaningful human activity ultimately revolves around the self-interested pursuit of power and resources (e.g., Bourdieu 199ob, 122; Bourdieu 1977, 82; see also Bourdieu and Wacquant 1992, 117-120). Thus, his theory cannot fully account for activities that surpass the realms of instrumentality and exchange (Adkins 2004, 14; Fowler 2003, 475-476; Urban 2005, 169-173).

Nevertheless, in defense of Bourdieu's theory it is important to reiterate that the necessary catalyst for individuals' participation in the struggles of the religious field is religious interest (Bourdieu 1971a, 311-312; Bourdieu 1991a, 15-16). Laymen and specialists alike act religiously based on what they believe know in their bodies - to be right, not open calculation. Moreover, belief in supernatural powers and the salvation goods connected to them can actually generate both altruistic and self-interested behavior. On the one hand, the religious field often rewards unselfish behavior, thus encouraging the formation of altruistic habitus, by, for instance, construing generosity and helpfulness

2 Moreover, several recent studies apply Bourdieu's concepts of capital and habitus to an analysis of the various secular resources that lay individuals, often members of dispossessed minorities, can gain access to through religious organizations (Barrett 2010; Karner and Parker 2008; Norman 2011). 
as markers of piety (see Bourdieu 1998, 86-88). On the other, as scholar of religion Terry Rey and anthropologist Alex Stepick $(2013,14-15)$ have recently suggested, to fully account for individuals' behavior within the religious field it is important to also acknowledge the existence of salvation goods that advance health and prosperity in the here and now. In fact, the insistence that "proper" religion is only concerned with the hereafter, as well as the condemnation of religious activities aimed at this-worldly concerns and often engaged in by marginalized groups in dire material circumstances, constitute discursive strategies employed by dominant groups and religious elites to bolster their status within the field. Sometimes, these strategies have even been endorsed by scholars of religion (see Orsi 2003, 170; Rubin, Smilde, and Junge 2014, 14).

Bourdieu's theorizations concerning religion do not foreground the concept of habitus. According to him, religious specialists' struggles in the religious field are ultimately about the legitimate power to influence lay people by inculcating in them a particular religious habitus. Bourdieu (1971a, 318-319; 1971b, 11; 1991a, 22) thus acknowledges the existence of a religious habitus, the "generative basis of all thoughts, perceptions, and actions conforming with the norms of a religious representation of the natural and supernatural world." His interest in this religious habitus, however, does not seem to exceed its role as a stake in the competition for power between religious professionals (Verter 2003, 157).

Bourdieuan adaptations of the concept of habitus to research on religion have, regardless, become more common in recent years. In this scholarship, the concept is usually employed to denote a practical worldview that results from active participation in a particular religion (Collins 2009; Martin 2012, 87-91; Sutcliffe 2006; cf., Wood 2007, 71-75, 156-163). The use of the concept, in other words, implies that a common way of life, more than explicitly stated beliefs, is what members of a faith group share. Many studies that employ the concept discuss conversion or other kinds of self-willed changes in one's religious orientation. That is, they focus on processes in and through which a new habitus is acquired (Coleman 2000, 117-142; Csordas 1997; Csordas 1994; Trulsson 2010; Winchester 2008), and on the influence of the original habitus on the emerging one (Fer 2010; Shanneik 2011; Trzebiatowska 2008). Other contributions, for their part, examine various situations resulting from religious pluralism, such as the formation of minority habitus, the effects of cultural domination on the habitus of marginalized groups, and the collisions between different habitus more generally (Gray and O'Sullivan Lago 2011; Hornborg 2005; Kühle 2012b; Rey 2005). In practice-oriented research, moreover, the concept of habitus supports inquiries into religion-in-action: the generation of religious actions and perceptions in particular situations (Bell 1992; McNally 1997; Mitchell and Mitchell 2008; Morgan 1998). 
Due to Bourdieu's cursory treatment of habitus in his writings on religion, scholars of religion working with the concept have often bypassed his explicit claims about religion and have focused instead on what he has to say about other dimensions of social life. Some have even opted to bracket Bourdieu's conceptual apparatus altogether, combining his understanding of habitus with, for instance, theories of embodiment or ritual theory (e.g., Bell 1992; Coleman 2000; Csordas 1997; Csordas 1994; Morgan 1998). According to Bourdieu, however, field, capital, and habitus acquire their meaning from the relations they have with each other, which is why it is important to take into account all three concepts when analyzing social phenomena (Bourdieu and Wacquant 1992, 94-101). Nevertheless, this does not mean that one must rely in equal measure on all of them. In fact, many of Bourdieu's own studies foreground some concepts at the expense of others - such as his famous analysis of taste and social class in Distinction (Bourdieu 1984), which focuses on habitus and capital.

This book is about the daily, domestic religiosity of displaced Karelian Orthodox women - their basic religious activities, and their ways of thinking, speaking, and feeling about religion. I investigate the women's present-day religion essentially as an outcome of their past practices and experiences, with the concept of habitus as my primary analytical tool. My reading of Bourdieu is a "second-degree reading" (Hanks 2005, 69) in that I rely more on his overall theory of practice than on what he explicitly says about religion. However, in line with Bourdieu's relational vision, I examine the interviewees' religious habitus in connection with the notions of religious field and religious capital. I particularly make use of these two concepts when widening my analytical scope from the immediate context of the Orthodox women's domestic and familial lives to the broader social and religious currents influencing their behavior. Nevertheless, the focus always remains squarely on the women. My analysis does not therefore comprise a comprehensive portrait of the Finnish religious field, or even its Orthodox Christian subfield. Rather, it offers a partial and localized micro-level perspective on these fields. In other words, it provides a view of the Finnish religious field as seen from the relative position of the informants.

\section{Religion as Habitus}

\section{Practice à la Bourdieu}

According to Terry Rey $(2007,92)$, habitus is the "single most important concept in Bourdieuian theory for the study of religion chiefly because of its trenchant power for explaining the nature of human belief and practice, which are obviously so fundamental to religion at large." Judging from the growing amount 
of discussions concerning Bourdieu's concept of habitus within religious studies, Rey's opinion is shared by many others - including myself. However, while habitus can be viewed as a most convincing place to locate religious belief (Rey 2007,129 ), to grasp habitus one needs to turn from Bourdieu's work on religion to his theory of practice.

Bourdieu's theory of practice aims at identifying and accurately describing the practical understanding that people acutely enmeshed in certain social relations have of these relations (Bourdieu 1990a, 59-61; Bourdieu 199ob, 102103; Bourdieu 1977, 1-2, 16-22, 37-38; see also King 2000, 419-422). According to Bourdieu, what spurred him to focus on practice was the realization that the traditional standpoint of the social scientist - the position of the impartial and uninvolved observer - invites him or her to succumb to a serious theoretical distortion: that of presenting as the source of people's practices an abstract model of these practices. "[T]here is an enormous difference between trying to understand the nature of matrimonial relations between two families so as to get your son or daughter married off (...) and trying to understand these relations so as to construct a theoretical model of them," he explicates (Bourdieu 1990a, 6o).

Bourdieu argues that theoretical models constructed from an outsider's point of view miss out on several crucial features of practice. First, they fail to take into account the situationality of practice. Practice always occurs in a concrete and unique situation which is evolving and taking form in the present moment (Bell 1992, 81; Bourdieu 199ob, 81). It adjusts itself to the emerging dynamics of the event and participates in their constitution. Furthermore, these models also overlook the practical, instrumental, and strategic nature of the aims and motivations that guide practice (Bell 1992, 82; Lovell 2000, 27). This is to say, in their actions individuals, for the most part, do not adhere to explicit rules. Instead, their ability to act successfully in particular situations results from their practical command of the workings of the social world.

Practice, as characterized above, is prone to routinization. In day-to-day social life, activities tend to follow along familiar lines. Routinization is integral to the constitutive effects of practice, since it is responsible for social reproduction (Giddens 1984, 6o, 64, 282; Heiskala 2000, 98). Nevertheless, alongside the repetitive tendencies of practice, it is important to acknowledge the creative capacities inherent in practice as well. Bourdieu ties these to temporality: the generation of practices is dependent on the individual's capacity to anticipate the imminent future of the emerging situation (Bourdieu 2000, 142-144; Bourdieu 1990b, 55-56; see also McNay 2000, 39-44; Postone, LiPuma, and Calhoun 1993, 4). This orientation towards the upcoming means that, although actors mostly act along familiar lines, they are also capable of improvisation and innovation. 
This brief introduction alone illustrates why a focus on practice makes for a superb approach to studies of lived religion. The main benefit of practiceoriented perspectives is that they direct scholars' attention away from readymade categories and towards religion-in-the-making (Bender 2012, 280-283; Bender 2003, 7-8; Hall 1997a, xi; Sutcliffe 2006, 298-299). In this vein, a focus on practice allows for inquiries into the logic behind the generation of religious activities, and into the oscillation between routines and improvisation that these activities demonstrate (McNally 1997, 147-148). Moreover, a focus on practice foregrounds the "practical coherence" characterizing lived religion (McGuire 2008, 15-16). From the point of view of the common believer, religion needs not constitute a logically coherent system as much as it needs to make sense in one's daily life, and to be effective in accomplishing desired ends. A focus on practice also brings to the fore the performative dimension of practices, establishing religious activities as world-making and self-making activities (Morgan 1998, 3-4, 204-205; see also Mitchell and Mitchell 2008, 83-85; Winchester 2008, 1753-1754). Finally, a focus on practice makes evident how lived religion unfolds within the interplay of structure and agency, bringing issues of power to the fore (Bender 2003, 6, 167-168n2; Orsi 2010, xxxvii-xlii; Orsi 1997, 14-16).

\section{A System of Socialized Senses}

The concept of habitus essentially constitutes Bourdieu's take on how practice should be understood (Bourdieu and Wacquant 1992, 121). ${ }^{3}$ In habitus, Bourdieu identifies and captures a complex, multilayered phenomenon: the generation of human actions and the constitution of the principle of their generation, as well as the construction of the social being and the social world, through these very same actions (Bourdieu 1990a, 12-13, 124-126; Bourdieu 199ob, 53; Bourdieu and Wacquant 1992, 121; see also Maton 2008, 53-55). A higher-level objective that Bourdieu sets for the concept is to overcome the dualism between objectivism and subjectivism or, put another way, structure and action. In his most famous definition, Bourdieu (199ob, 53) describes habitus as

systems of durable, transposable dispositions, structured structures predisposed to function as structuring structures, that is, as principles which generate and organize practices and representations that can be objectively adapted to their outcomes without presupposing a conscious

3 Many thinkers prior to Bourdieu have included a concept of habitus in their work. Bourdieu (1990a, 12) himself makes mention of G. W. F. Hegel, Edmund Husserl, Weber, Durkheim, Mauss, and Erwin Panofsky. Moreover, the history of the concept actually dates back all the way to Aristotle and Thomas Aquinas (Mellor and Shilling 2010b, 207; see also Hanks 2005, 69-72; Maton 2008, 55-57). 
aiming at ends or an express mastery of the operations necessary in order to attain them. Objectively 'regulated' and 'regular' without being in any way the product of obedience to rules, they can be collectively orchestrated without being the product of the organizing action of a conductor.

For Bourdieu $(1977,15)$, then, habitus designates a system of dispositions, which is first inculcated during childhood and afterwards regularly reinforced by "calls to order" from individuals endowed with similar dispositions. Dispositions are tastes and preferences concerning all aspects of life ranging from, say, aesthetics to parenting and to ideas concerning success (Bourdieu 1984, 170, 466-467; see also Martin 2012, 74-80). Because they are acquired in encounters with other people, various social divisions - such as class, gender, race, ethnicity, and religion - leave a mark on them (Bourdieu 199ob, 6o; Bourdieu 1984, 101; see also Lawler 2004, 112; Reay 2004b, 434). Moreover, the system of dispositions endows individuals with a capacity to intuit what in each situation constitutes suitable behavior "for the likes of us," for people occupying the same position in social space (Bourdieu 1984, 466-467; see also Maton 2008, 57-6o). This functioning of habitus as social orientation is responsible for the unconducted collective orchestration of practices.

Besides referring to them as tastes and preferences, Bourdieu $(1977,124)$ also speaks of dispositions as socially informed, embodied senses. "[T] he principle generating and unifying all practices," he states,

is nothing other than the socially informed body, with its tastes and distastes, its compulsions and repulsions, with, in a word, all its senses, that is to say, not only the traditional five senses (...) but also the sense of necessity and the sense of duty, the sense of direction and the sense of reality, the sense of balance and the sense of beauty, common sense and the sense of the sacred, tactical sense and the sense of responsibility, business sense and the sense of propriety, the sense of humour and the sense of absurdity, moral sense and the sense of practicality, and so on.

This idea has appealed to many scholars of religion, for it makes possible the conceptualization of individuals' religious activities as the engagement and living through of their sense of the sacred (McNally 1997, 148; Trulsson 2010, 345-346), "sense of ritual" (Bell 1992, 80), or overall "religious senses" (McGuire 2008, 99-100).

Habitus, as a system of dispositions, can also be understood to imply socialized subjectivity (Bourdieu and Wacquant 1992, 126; see also McCloud 2007, 
168; Ortner 2006, 109-110). Subjectivity here refers to a non-articulated and non-reflected aspect of the self, which is realized in action and shows in our predispositions, orientations, tendencies, attachments, emotional judgments, style, and so on. It functions as the basis of identity: a reflective and articulated, continually evolving narrative conceptualization of "who I am" (e.g., Utriainen, Hovi, and Broo 2012, 188, 198-199). Furthermore, what Bourdieuan social theory accomplishes particularly well is explicating the role of embodiment in subject formation (Hollywood 2002, 95-96, 99-100; Krais 2006, 127-128; McNay 2000, 13-14, 25-26, 32-36). ${ }^{4}$ According to Bourdieu (2000, 141; 199ob, 69-70, 72-73), both the acquisition and the reproduction of cultural schemes take place primarily on the level of the body. Habitus therefore actually refers to knowledge that has been learned by the body. It is not knowledge that one can necessarily apply at will, but a way of inhabiting a world, a part of what one is.

It is important to study practice from a long-term perspective, notes anthropologist Sherry Ortner (2006, 9; see also 1989, 12, 193), because the "playing out of the effects of culturally organized practices is essentially processual and often very slow." Bourdieu's account of habitus can be seen to answer Ortner's call, for it emphasizes the historical depth of dispositions. Since the individual's experiences are always structured based on his or her present habitus, which is the effect of past experiences, habitus includes a bias towards early experiences (Bourdieu 2000, 160-162; Bourdieu 199ob, 53-54, 56, 6o; Bourdieu 1984, 109-110; Bourdieu and Wacquant 1992, 130). This inertia of habitus ensures the relative stability of dispositions through time. For Bourdieu, then, habitus is embodied history, or the "active presence of the whole past of which it is the product" (Bourdieu 199ob, 53-56; see also Maton 2008, 52). However, at all times habitus is also modified by new experiences (Bourdieu and Wacquant

4 The notion of habitus is in many ways compatible with poststructuralist discussions concerning subject formation, particularly those of philosophers Michel Foucault and Judith Butler (Skeggs 2004b, 83-84). The basic idea in poststructuralist theories is that subjectivity is not something that exists prior to social influences. Instead, the subject is shaped in interactions with regulatory forces. However, in these same interactions, the subject ends up reproducing and reconfiguring the social world. A common tenet of the theorizations of Bourdieu, Foucault, and Butler is that they all conceive of subjectivity as formed through practice. Foucault highlights the importance of analyzing practices and technologies of power and truth, and their relationships with different conceptions of the self (Foucault 2000, 277, 290; Foucault 1985, 11; see also Skeggs 2004b, 78). For Butler, gender is continuously constituted as an effect of reiterative practices, which cite existing discourses and procedures and inscribe them on the body of the actor (Butler 2006, xv, 185, 192, 198-199; Butler 1993, 12, 15; see also Hollywood 2002, 94-96, 112-113; McNay 2000, 33-34). 
1992, 133; Bourdieu 1990a, 116). As the individual accrues certain kinds of experiences, the influence of others slowly wears out.

Bourdieu's theory suggests that dispositions acquired during early learning commonly form the most compelling and stable elements of habitus. The earlier an individual enters into the "game" of a particular field, "and the less he is aware of the associated learning, the greater is (...) his unawareness of the unthought presuppositions that the game produces and endlessly reproduces, thereby reproducing the conditions of its own perpetuation" (Bourdieu 199ob, 67; see also Bourdieu 2000, 164-167). All in all, Bourdieu's descriptions concerning the acquisition of habitus resemble sociologists Peter Berger and Thomas Luckmann's outline of primary socialization as something semi-automatic and semi-inevitable (Berger and Luckmann 1971, 154-155; see also Kühle 2012b, 118-119; Martin 2012, 49-51; Stone 2001, 14). According to Berger and Luckmann $\left(1971,11^{-157)}\right.$, the worldview into which the child is socialized in his or her primary group appears to the child as natural and self-evident for the simple reason that he or she lacks experience of other worldviews. Since the child forms his or her identity with respect to this particular worldview, the effects of primary socialization usually remain strong throughout life.

In his discussions on the formation of habitus, Bourdieu does not pay much attention to the shaping of habitus in later life: to processes of secondary socialization and re-socialization. This weakness in Bourdieu's theory has been addressed by several critics and re-interpreters, including some scholars studying religious conversion and re-awakening, who have reprehended his account of habitus on the grounds that it neglects conscious processes of habituation (Mahmood 2005, 135-139; Noble and Watkins 2003, 523-525, 535-536; Trulsson 2010, 57-61). Bourdieu's lack of interest in intentional dimensions of learning, however, does not mean that such aspects of learning are incompatible with his theoretical apparatus. Indeed, his understanding of human action accounts also for situations that involve strategic cultivation of habitus (Bourdieu and Wacquant 1992, 131). Nevertheless, in the last instance social action always contains also dimensions to which the actor remains blind (Bourdieu 199ob, 53-54, 67, 73-74; see also Akram 2013, 51, 55-56; Bell 1992, 82, 87, 108-109). This, in my reading, is the crux of Bourdieu's argument.

Bourdieu's inclination to picture habitus as an unconscious resource has also given rise to another accusation. In the view of many scholars, this emphasis renders his interpretation of habitus unrealistically unified and stable (e.g., Noble and Watkins 2003, 524-525, 529-530; Reay 2004b, 437-438; Sewell 1992, 15-16; Skeggs 2004a, 25, 27). It describes a world in which individuals are "fated to reproduce the conditions of their existence" (Mellor and Shilling 2010a, 30,34). This, however, is an overstatement. Instead of being deterministic, Bourdieu's theory simply does not paint an optimistic picture about 
the possibility for change (Fowler 2003, 486; Lovell 2000, 31; McCloud 2012, 4; McNay 2000, 36-39). As ethnohistorian Monique Scheer (2012, 204) explains, "habitus must be static and binding to a certain extent, if it is to be more than just a loose cloak that can be thrown off on a whim. At the same time, (...) it leaves space for behaviors not entirely and always predictable, which can also instantiate change and resistance rather than preprogrammed reproduction." Furthermore, when habitus is considered in connection with field, Bourdieu's account becomes more balanced. The relationship with field, in other words, brings dynamism and instability to habitus (Hardy 2008, 131-132; McNay 2000, $51,53)$.

\section{Habitus and Field - a Revisit}

Practice does not result simply from the dispositions of habitus, but is generated in the interaction between habitus and field. To be more specific, practice reflects the relations between the individual's habitus, his or her accumulated capital within a particular field, as well as the current state of the field as a whole (Bourdieu 2000, 149-151; Maton 2008, 51-52). Bourdieu describes the relationship between habitus and field as "double and obscure" (Bourdieu and Wacquant 1992, 127-128). On the one hand, involvement in the "game" specific to a field influences the dispositions of habitus. On the other, these dispositions establish the field as a meaningful and valuable world. In Bourdieuan vocabulary, what makes people get together and compete with each other in a particular field is interest (Bourdieu and Wacquant 1992, 116-117; Bourdieu 1990a, 87-88; see also Grenfell 2008a, 154). It is based on the tacit acceptance of, or practical belief in, the rules of the game and the stakes the game is concerned with. Interest is a precondition of the formation of any field.

"Practical sense," "feel for the game," and "strategy" are terms with which Bourdieu describes the generation of practices within a field. In the previous section, I mentioned socialized senses as one depiction of the dispositions of habitus. Practical sense, or the sense of practice, captures this idea in the most general form. It refers to the individual's capacity to recognize situations, to anticipate their progress, and to react to them through his or her actions: to act successfully in various social environments and events (Bourdieu 2000, 138-139; Bourdieu 1990a, 62-63; see also Lovell 2000, 27; McNay 2000, 39). Practical sense, that is, describes habitus actualized in the present moment and within the flow of time.

The feel for the game, for its part, describes practical sense as attuned with a particular field. It is a way of accounting for the actions of individuals supremely practiced at a particular game. The practices of these people are not executed as obedience to rules or calculated moves, but are the result of practical strategies and regulated improvisation (Bourdieu 2000, 142-144; Postone, LiPuma, and 
Calhoun 1993, 4; Scheer 2012, 202). In fact, according to Bourdieu (1990a, 62-63), " $\mathrm{n}]$ othing is simultaneously freer and more constrained than the action of the good player." It "presupposes a permanent capacity for invention, indispensable if one is to be able to adapt to indefinitely varied and never completely identical situations." However, this freedom of invention and improvisation is simultaneously regulated by the limits of the game (Bourdieu 1990b, 53-56, 66; Reay 2004b, 435). Some actions are simply impossible within its boundaries.

Bourdieu states that for virtuoso players, whose habitus is perfectly attuned to the surrounding field, the field constitutes a common-sense world to which they take like "ducks to water" (Bourdieu and Wacquant 1992, 127-128; Bourdieu 1990b, 56-57, 68; McNay 2000, 38). This, however, describes an ideal situation only, since societies do not constitute homogeneous totalities. Instead, they include numerous fields which are in a constant process of internal change and external conflict. When habitus is formed through participation in several, more or less incompatible fields, it comes to harbor inherent conflicts and tensions (Bourdieu 2000, 160; see also McNay 2000, 51-72). It does not fit any one field smoothly. Furthermore, if the fields evolve, habitus may fall out of pace with them (Bourdieu and Wacquant 1992, 129-130, 136; Bourdieu 199ob, 62). In a situation where there is considerable mismatch between habitus and the surrounding fields, the living through of habitus becomes more problematic. The social universe loses some of its common-sense character, which brings unpredictability to the individual's actions.

According to Bourdieu, modern societies are characterized by growing differentiation of types of fields and capital (Calhoun 1993, 77; Engler 2003, 452). As a result, the habitus of individuals inhabiting the same society grow more different with respect to each other. However, while Bourdieu acknowledges the increasing external heterogeneity of habitus in modern societies, he does not make a similar statement with respect to their internal heterogeneity. This oversight has led some scholars to question the applicability of Bourdieu's concept to modern and late-modern societies (e.g., Archer 2010, 286-288; Cantwell 1999, 225). Others, including myself, maintain that Bourdieu's theorization of habitus, when properly thought through, is indeed able to account for practice in more complex societies as well.

The level of differentiation in the social world is directly commensurate with the level of intricacy, multidimensionality, and internal contradiction in the habitus of its inhabitants. This means that the complexity of modern societies precludes the emergence of a complete harmony between an individual's habitus and the fields he or she participates in (Krais 2006, 123-124, 131; McNay 2000, 52). The modern individual, in other words, is bound to face 
situations in which the habitus does not provide him or her with an unequivocal sense of how to proceed, but may even point towards several opposite courses of action. These experiences can result in the individual becoming more conscious of the arbitrary nature of his or her dispositions (Adkins 2003, 25-27; Krais 2006, 130; McNay 2000, 66, 68).

For Bourdieu, awareness and reflection commonly ensue only from the breakdown of the conventional social order (Bourdieu and Wacquant 1992, 131; see also Reay 2004b, 437-438). However, when the characteristics of modern and late-modern societies are taken into account, it is possible to argue that the emergence of these capacities does not require any particular crisis (Adkins 2003, 25-27; see also Akram 2013, 57; Kühle 2012b, 118). Instead, partial and situated possibilities for reflection also arise within day-to-day life. Sociologist Lisa Adkins has argued that this kind of reflectiveness need not even be considered as standing in contrast with habitual action (Adkins 2003, $3^{2-35}$; see also Krais 2006, 130; Reay 2004b, 437-438). On the contrary, if dissonances between habitus and field are constitutive of the individual's habitus, heightened awareness can become part of his or her habitual repertoire of responding to the social world.

\section{Habitual Agency?}

The question of agency has been an integral part of social scientific debates at least since Weber and Durkheim (Rapport and Overing 2000, 1-2). The notion of agency originates from Western philosophical discussions that emphasize an autonomous and rational individual who acts in the world following his or her best interests (Asad 2003, 73-75; Messer-Davidow 1995, 25-29; Meyer and Jepperson 2000). A central problem with these classic formulations of agency, however, is that they often downplay the cultural underpinnings of the intentions, motivations, and beliefs of individuals. Thus, anthropologist Talal Asad $(2003,72-73,78 ; 1993,13,167)$, for instance, has convincingly argued that investigations into the local conditions of subject-formation are required to understand agency in any comprehensive manner. Practice theory, moreover, has been seen to answer this call for more situated accounts of agency; after all, it is founded on the premise that actors are always socially embedded. Based on practice theory, it is possible to argue that, whereas the capacity for agency is a universal human attribute, actual agency is a capacity of a culturally constituted subject (Ahearn 2001, 112; Emirbayer and Mische 1998, 974, 1003; Ortner 2006, 130-131, 135).

Historically, agency fueled by religion has been a problematic topic for social scientists. In so far as agency has been tied to the modern, liberal, 
and rational ideal of the subject, focusing on religious agency has been difficult - for scholars have tended to view religion as something antithetical to modernity (Bracke 2008, 61-63; Braidotti 2008, 2; King 2005, 1-2; Mack 2003, 150, 159-160). Within mainstream feminist theory, moreover, religion has conventionally been understood as unequivocally oppressive to women, which has made an oxymoron out of the idea of religious women's agency.

Nevertheless, during recent decades, studies focusing on the agency of religious women have proliferated. These have commonly targeted gendered and women's agency within particular religious sub-cultures, especially conservative and patriarchal religions. ${ }^{5}$ Originally, the question that seemed to haunt feminist scholars involved in this strand of research concerned the reasons why women would deliberately support or turn to religious ideologies that oppressed them. These early investigations have later been criticized on the count that they misattribute to religious women feminist aims and categories of thought, while, simultaneously, neglecting those aims and categories of thought (particularly concerning religious piety) that are important to the women themselves (Abu-Lughod 1990, 47; Mahmood 2005, 5-14; Woodhead 2003, 68-71).

At the turn of the third millennium, many scholars of gender and religion begun to stress inquiries into the particular contexts, discourses, structures, and powers that influence religious women's agency (Avishai 2008, 409-410; Bracke 2003, 336-337; Furey 2012, 17-20). The most influential single study that helped to turn the scholarly tide was anthropologist Saba Mahmood's (2005) investigation into Egyptian Muslim women. Mahmood (2005, 18, 23), leaning on the work of philosophers Michel Foucault and Judith Butler as well as on Asad, conceptualizes agency as a "capacity for action that specific relations of subordination create and enable," emphasizing that agency resides in the multiple ways in which subjects live norms, not only in actions that resist norms. She therefore advises scholars not to define the meanings and forms of agency prior to analysis, but to explore them within the context of action under study (Mahmood 2005, 14, 34). Since the publication of Mahmood's research, numerous scholars have taken heed of her instructions in their work (Avishai 2008; Bilge 2010; Bracke 2008; Isik 2008; Jacobson 2006; Kościańska 2009; Lindhardt 2010; Longman 2008; Parashar 2010; Plancke 2011; Smid 2010).

5 There is also a growing body of research into the agency of women involved in different post-secular spiritualities, such as various healing practices (e.g., Utriainen 2014). Inquiries into the agency of religious men, for their part, are still quite rare (see, however, van Klinken 2013). 
Indeed, Mahmood's observations also constitute one starting point of my take on agency in this study.

Nevertheless, Mahmood's account of agency has also been criticized. Religious ethicist Elizabeth Bucar (2010, 669-670, 673-674), for instance, argues that it does not sufficiently admit to spontaneous and creative action. According to Bucar, historically and culturally specific skills can also be put to unorthodox use. Thus, she speaks of "creative compliance" and "complicit resistance" as possible ways of inhabiting religious traditions - ways that account for critical action as well (Bucar 2010, 678-680; see also Ahearn 2001, 119; Campbell 2005, 5-7).

My understanding of agency is based on sociologist Lois McNay's (2000; see also 2004; 2003; 1999) reading of Bourdieuan social theory. Bourdieu's theorizations have, heretofore, not been employed much in studies focusing on religious women's agency (see, however, Alayan and Yair 2010). This lack of Bourdieuan applications reflects the currency, within feminist theory, of the notion that Bourdieu's idea of habitus is excessively pessimistic when it comes to the possibility of dissent, resistance, and change (McNay 2004, 180-181, 185; McNay 2003, 142-143). I have already voiced my disagreement with this criticism; that is to say, I side with those interpreters of Bourdieu who consider his work a feasible basis for a theory of agency (Lawler 2004, 112; Reay 2004b, 433; see also Lindquist 2006; Winchester 2008).

In her account, Lois McNay $(2003,142-143)$ grounds agency on the temporality of Bourdieu's conceptualization of habitus: on Bourdieu's insistence that the formative effects of past experiences are always actualized in concrete situations. The anticipatory dimension that is part of the living through of habitus is captured in Bourdieu's term "practical sense." The sense of practice ensures that habitus is not guided solely by the past but involves interplay between different temporal orientations (Bourdieu 2000, 206-213). This dynamic, moreover, is where McNay situates agency. To her, agency is an "act of temporalization" where the individual acts in the present guided by his or her practical sense of the forthcoming, which builds on his or her past experiences of related situations (McNay 2000, 23, 38-40, 46-47; McNay 2003, 144).

Similar to Saba Mahmood, also Lois McNay emphasizes the complex relations between human activity and surrounding social formations. She suggests, moreover, that Bourdieu's concept of the field helps in perceiving the intricate relations between agentic action and social structure (McNay 2000, $51,71)$. The idea that the individual's capacities of action are produced within a number of fields allows for a sophisticated perspective on the power relations surrounding the individual, and on the various resources at his or her disposal. Agency, from this outlook, is never about simple resistance to a 
singular dominant order. Autonomy and subordination are realized in individuals' lives in a more nuanced way - and agency concerns the negotiation, through practice, of the "often discontinuous, overlapping or conflicting relations of power" within which individuals are enmeshed (McNay 2000, 16-17; McNay 2004, 175).

It is common for theories of agency to emphasize the future-orientation of agentic action. Often, this orientation takes the form of intentionality and projects; agency is seen to inform activities that clearly supersede mere habits (e.g., Ortner 2006, 134-136; Sewell 1992). For instance, in her description of religious agency, sociologist Laura Leming $(2007,74)$ understands agency "as a personal and collective claiming and enacting of dynamic religious identity," and emphasizes that "when religious agency is operative, religion (...) is consciously, rather than repetitively, enacted." Several scholars, however, have pointed out that coupling intentionality with agency is debatable, since the relationship between intentions and outcomes of action is, in reality, complex and problematic (Asad 1993, 15-16; Giddens 1984, 9; Ortner 2006, 131-136).

In her discussion of agency, McNay $(2003,143)$ explicitly distinguishes the anticipatory dimension that is part of the living through of habitus from the idea of the project. Orientation towards the future does not only characterize actions fueled by projects but is part of all action. This same point is emphasized also by sociologists Mustafa Emirbayer and Ann Mische in their theorization of agency. According to Emirbayer and Mische, agency is a "temporally embedded process of social engagement, informed by the past, but also oriented toward the future and toward the present" (Emirbayer and Mische 1998, 963-964, 1012; see also Bourdieu 2000, 221-223). It results in action that, depending on the situation, can be primarily aligned with the past, immersed in the present, or directed towards the future. Thus, for Emirbayer and Mische, all social action, even action primarily adjusted with the past, includes an agentic element (Emirbayer and Mische 1998, 976, 1004; see also Akram 2013, $47,5^{1-52)}$.

In this book, I maintain that habitus informs the agentic capacities of the individual. It circumscribes the framework of possibilities, probabilities, improbabilities, and impossibilities within which he or she acts. Moreover, I also conceive of agency as actualized in the moment of action and as constitutive of all action. This Bourdieuan formulation of agency, I contend, makes it possible to also approach agency as it is realized in semi-conscious action. In fact, it is particularly suited for inquiries into the kind of agency that MarjaLiisa Honkasalo (2009, 61-64; 2008a, 498; 2008b, 83-85, 207-210) calls small agency: agency embedded in the routine, everyday practices of ordinary 
people. As an account of agency it is inclusive, certainly too inclusive for those who want to separate intentional agency from routine action. For my purposes, however, it is appropriate, because my aim is in unveiling agentic possibilities embedded in habitual religious activities.

\section{Capturing Habitus}

My reasons for choosing Pierre Bourdieu's social theory as the theoreticalmethodological foundation of the research are several. On the one hand, the promise shown by his concept of habitus with respect to the lived religion paradigm has either been implied or explicitly stated in many previous accounts (Edgell 2012, 251; McGuire 2008, 99-100; Orsi 1997, 16; Sutcliffe 2006, 298-299). Nevertheless, full-blown adaptations of habitus to empirical research remain "surprisingly" few (Edgell 2012, 251). On the other hand, Bourdieu's understanding of the religious field and emphasis on sociology as a reflective enterprise also benefit the study of lived religion. They facilitate the integration of questions concerning the construction of the category of religion within the research at hand, as well as within the academia in general, into analyses (Wacquant 1992, 36-40; see also Bourdieu 2010; Grenfell 2008b, 225-227).

With this book, I add to ongoing theoretical discussions concerning the study of religion-as-practiced by offering an interpretation of the religion of evacuee Karelian Orthodox women as habitus. Habitus, I argue, constitutes a particularly apt tool for approaching their kind of religion, because it accounts for the embodied, semi-conscious, and iterative yet generative nature of practice (see also Berzano 2011, 69-70). Combined with the concept of field, habitus also provides a perspective into dynamics of religious activity in the context of complex social changes. Both these points of view need to be taken into account when the aim is to understand lay practitioners' long-term involvement in religion.

But how does one study habitus? After all, it is not possible to see it directly, only its effects in practices and perceptions (Akram 2013, 46-47; Maton 2008, 62-63). The key is to look at habitus in connection to field, and to anchor this analysis both historically and contextually. To capture a particular habitus, in other words, it is necessary to reconstruct the social conditions that have produced it (Bourdieu 1984, 123-124; Bourdieu and Wacquant 1992, 104-107; Grenfell 2008b, 222-225). This involves analyzing the social trajectory of the individual through his or her life: acquainting oneself with the organization and evolution of the fields he or she has participated in, with the positions he or 
she has held within these fields, with the volume and composition of capital in his or her possession, as well as with the social trajectories of his or her parents.

I approach the habitus of the women I study by delving into their trajectories as religious practitioners in the sociohistorical context of 2oth and 21st century Finland. In the course of the analysis, I focus on specific layers of their habitus and trace the effects of these layers in their religious activity (see Kauppi 2000, 125-126). Questions concerning the women's position in the religious field and the capital in their possession I address when necessary, mindful of the limits of my micro-level approach as regards the broader configurations of the Finnish religious field.

One fundamental methodological choice on my part has been to approach habitus through interview material. On the one hand, I read the interview accounts of the women I study to uncover their social trajectories. On the other, I also view the accounts as manifestations of their habitus. To explain how this works, it is necessary to look at what Bourdieu says about habitus in connection to language. According to Bourdieu (1990a, 131), "habitus is at once a system of models for the production of practices and a system of models for the perception and appreciation of practices." In other words, habitus creates practices, opinions concerning practices, as well as classifications concerning both practices and opinions. These opinions and classifications can be understood as second order practices: they are practices about other practices. Moreover, they often come in the form of linguistic practices.

As I have discussed above, habitus is primarily not a conscious resource. With respect to discursive practices, this means that even though individuals are able to produce verbal explanations of what they are doing and why, these accounts remain tied to their dispositions. The actions of individuals thus always contain also motives and enforce also meanings that the actors are not able to access (Bourdieu 1991b, 89; Bourdieu 199ob, 53-54). More specifically, whereas individuals often see their practices as responses to particular circumstances, what they do not see is how their practices come to generate or redefine these very circumstances (Bourdieu 199ob, 69; Bourdieu 1977, 79-80; see also Bell 1992, 82, 87, 108-109; Bronner 2012, 33). The preconditions and consequences of this blind aspect of practice Bourdieu explains using his account of symbolic power.

For Bourdieu (1990a, 134-138), linguistic practices are always connected to symbolic struggles. In these struggles, actors within a particular field or across different fields compete for power to produce legitimate perceptions and appreciations concerning the social world. This symbolic power, as Bourdieu names it, hinges on the complicity of those who submit to it. It is efficient only because individuals make use of discursive categories and classifications 
genuinely believing, due to their involvement in the activities of a particular field, in the legitimacy of these discursive structures (Bourdieu 2000, 170-172, 177; Bourdieu 1991b, 164, 170; see also Hanks 2005, 77-78). In so doing, the individuals come to reinforce the vision of the world contained in them.

As to religion, what all this means is that Bourdieu's theory allows for the study of religious practices as well as practices "about" religion, including speech practices (Bender 2012, 278-279, 281; Bender 2003, 5, 90-116; see also Csordas 1997, 157-201). Originating from habitus, practices of speaking about religion follow particular senses, tastes, and life-styles. They commonly embrace particular religious interpretations of the world, recognizing their legitimacy. They, moreover, tap into differences between habitus to reinforce distinctions between social positions within the religious field. Practices of speaking about religion, in a word, are quite pregnant with the effects of habitus - hence making a good target for analysis.

However, to study habitus through interview material, I need not only account for the specifics of linguistic practice, but also for those of interview relationships. The most important characteristic of interview material, as research material, is that it is produced in interactions between the interviewer and the interviewees (Bourdieu 1999b, 608; Holstein and Gubrium 2003, 67-69; Kvale 1996, 42-44). This means that the researcher is an active participant in not just the processing and analysis of the research material but its creation as well (Utriainen 2010, 121-122; Utriainen 2002, 176-178).

The interaction between the interviewer and the interviewee is influenced by various factors, starting from overall conventions regarding conversation (Alldred and Gilles 2002, 155-157). As social scientist Eeva Jokinen (2005, 39) has noted, people generally take the role of research informant seriously: when being interviewed, they strive to describe their experiences sincerely and express their opinions accurately. However, various cultural norms still affect their accounts. For instance, it is commonly important for people to describe themselves in a positive light with respect to established notions of respectability and competence. In addition, while the interviewer has in mind a specific goal for the interview, interviewees often bring to the situation their own ideas and agendas concerning the process (Bourdieu 1999b, 6og). For example, recollections of past practices and events, which my material largely consists of, reflect both the significance of the past for the interviewee at the time of the interview and the interview situation itself, since individuals always narrate the past taking note of the present audience (Climo and Cattell 2002, 13, 16-17; see also Bender 2003, 136-139).

Interview material, moreover, is grounded in dialogue on an even more fundamental level, for, in producing their verbal accounts, individuals are 
dependent on collective discursive resources at their command (Gubrium and Holstein 2003, 43-45). Hence, the meanings established in these accounts are never completely private. For example, when describing the past, individuals always make use of, and position themselves in relation to, standard narratives concerning the past. In fact, the interview situation can be understood as an encounter and negotiation between two different interpretations of the social world: that of the interviewee and that of the interviewer (see Knott 1995, 206). With this being the case, it is important to analyze how these two relate to each other.

For the most part, individuals act in the social world following their socialized senses. Their bodies contain volumes of tacit knowledge that they cannot verbally articulate. Moreover, they often remain oblivious of core principles affecting their social position and particular perspective on the world. Nevertheless, when describing their actions, they often construct themselves as intentional, rational, and project-oriented actors (Altheide and Johnson 2011, 590-592; Bourdieu 1999b, 620-621). In the analysis, it is thus important to reach beyond the informants' interpretations, and to cast light on the conditions of their production: on the positional and situational nature of their knowledge and experiences concerning the social world (Gubrium and Holstein 2003, 39-41).

In his methodological reflections on the use of interview material in social research, Bourdieu (1999b, 6o9; see also 1991b, 54-56, 72-76) states that to properly take into account the particular characteristics of interview material requires two things: an analysis of the distance between the objective of the research as assigned by the researcher and as interpreted by the informant, as well as an analysis of the asymmetry between the social positions of the two parties. These measures help the researcher to decipher what the interviewee can legitimately know and say, and what he or she is likely to censor and what to emphasize, in the interview situation. Ultimately, the issue at stake is an effort to reduce the symbolic power exerted by the researcher over those researched.

My treatment of the interview material emphasizes it as a joint production and takes into account the specific conditions under which it is produced. In the course of the analysis, I interpret the material from several angles. In some sections, I look at what the women say about certain practices, beliefs, or events, and analyze these accounts as evidence of what they actually do, believe, and have experienced. At other times, I focus on their perceptions and appreciations concerning particular topics, which I analyze as examples of their practice "about" religion. And occasionally, I take under consideration the interaction between the interviewees and myself. All these layers are indicative 
of the women's habitus. Together, they make it possible to trace, from the interview material, the women's social trajectories and the positions they occupy in social space (Bourdieu 1999b, 618; see also Holstein and Gubrium 2003, 78-79).

Epistemological discussions within social sciences nowadays emphasize the positioned, partial, and dialogical nature of all knowledge - including research knowledge. In consequence, the researcher is required, to the best of his or her ability, to reflect on his or her particular position in relation to the research (Altheide and Johnson 2011, 586-588; Doucet and Mauthner 2002, 134, 137-138; Utriainen 1998b, 292-294). For Bourdieu, reflexivity is ultimately about employing the same epistemological approach to the research process and the researcher than to those researched (Deer 2008b, 200-202; Grenfell 2008b, 225-227; Wacquant 1992, 36-46). The researcher is able to constitute the point of view of the object of research in social space only after conducting an auto-analysis of his or her own point of view in that space (Bourdieu 1999b, 625-626; see also Bourdieu 2010, 5-6; Wood and Altglas 2010, 10-16). This analysis has to concern the researcher's relationship to the field under study and take up his or her attachments within the academic field. The primary focus of reflection, Bourdieu notes, should be the researcher as social scientist, not as an individual (Bourdieu 2010; see also Wood and Altglas 2010, 11-12).

In this book, I strive for openness and reflexivity as advocated by Bourdieu. Most of my reflective work concerns epistemological and methodological issues: choices concerning concepts, theories, methods, and methodology. However, I also engage in self-reflection as regards my relationship with the interviewees and my positioning with respect to the overall research topic. I discuss these issues throughout the research, including the next chapter where I reconstruct the processes of producing, organizing, and analyzing the research material. 